\title{
Association between surface ozone and solar activity
}

\author{
R. Samuel Selvaraj, S. Tamil Selvi, ${ }^{*}$ and S.P. Vimal Priya \\ *Dhanalakshmi Srinivasan College of Engineering \& Technology, Chennai-603 104. \\ Presidency College, Department of Physics, Chennai-600 005. \\ samuelselvaraj.r@rediffmail.com; tssekar9773@yahoo.com
}

\begin{abstract}
The possible relationship between surface ozone and smoothed sunspot numbers (SSN) has been studied. The sunspot data were collected from Udaipur Solar Observatory for 1996-2004. Surface ozone has been measured at Tranquebar $\left(11^{0} \mathrm{~N}, 79.9^{0} \mathrm{E}\right)$, a tropical rural coastal site on the east coast of southeast India, during the same period. The measurements have shown that there exists a significant diurnal cycle/oscillation of average ozone with a maximum concentrations in the afternoon and average minimum ozone concentration at sunrise. Ozone measurements have also shown that the average higher concentrations [ $23 \pm 9 \mathrm{ppbv}]$ in May and lower concentration $(17 \pm 7 \mathrm{ppbv})$ in October at this site. Further, the increase in surface ozone in association with increase in sunspot numbers is observed during May and October.
\end{abstract}

Keywords: Smoothed sunspot numbers; surface ozone; significant diurnal cycle.

\section{Introduction}

Ozone belongs to the group of atmospheric trace gases. However, owing to its significant oxidizing ability and active interaction with solar ultraviolet radiation, ozone plays a significant part in ecology and radiation and dynamic processes in the atmosphere. For e.g., tropospheric photochemical processes with the participation of ozone and UV-B ultraviolet radiation can change the composition of the lower atmosphere. (Butukhanov \& Lomukhin, 2008).

The ozone measurements recorded during the $19^{\text {th }}$ century show that ozone concentration was about 10 Ppbv at mid latitudes over Europe and 5 Ppbv in tropical regions, with little variation through the year (Mickley et al., 1999). It is an effective greenhouse gas responsible for climate change Northeast and Southeast Indian regions has high potential for ozone formation because of increasing oxides of nitrogen (Nox) and high solar radiation (Staudt AC., 2003).

In this paper, we present ozone measurements which have been carried out for the first time in this region at Tranquebar, a remote rural and coastal site on the coromandal coasts of the Bay of Bengal, India.

\section{Location and instrumentation}

Tranquebar is situated on the eastern coast of India. There is no major industrial complex located in the town. The month May is the representative for the summer season (March-May). The weather at the site during May is very hot due to intense solar radiation. The day time temperature reaches above $40^{\circ} \mathrm{C}$ and night time above $30^{\circ} \mathrm{C}$. The site receives heavy rainfall only during northeast monsoon Oct- Dec which is the main rainy season (Singh \& Sontakke, 1999). The month January is the representative for the winter season (Jan- Feb). The month of July is the representative for the pre-monsoon season (Jun- Sep).

The ozone concentration in parts per billion by volume (ppbv) were estimated by neutral buffered potassium iodine (NBKI), $(\mathrm{Ph}=6.8 \pm 0.2)$ method, by bubbling a known volume of ambient air (21/min for $30 \mathrm{~min})$. This air is allowed to pass through the solutions containing $\mathrm{KH}_{2} \mathrm{PO}_{4}, \quad \mathrm{Na}_{2} \mathrm{HPO}_{4}$ and $\mathrm{KI}$, followed by spectrophotometer measurement of 12 at $352 \mathrm{~nm}$ wavelength. The ozone is estimated as $1 \mu \mathrm{l}$ ozone $\mathrm{ml}^{-}=$ $4.09 \times 10^{-} 6 \mathrm{~mol}$ I2 in $100 \mathrm{ml}$ (Perry \& Young, 1977). The ambient air sampling was carried out for collection of eight samples each times are given in Indian Standard Time (IST), which is ahead of the GMT by $5.5 \mathrm{~h}$. The sample has been collected for 10 days continuously in a month of Jan, May, July and Oct from May 1996 to Oct 2004. As this method is intended for the manual determination of ozone concentration for 30 minutes time averaged, a sharp peaks (pulses) in ozone concentrations are not observable. The NBKI method have been calibrated with UV photometric ozone analyzer (Model ozone 42 M, Environment S.A. May 2002) by running them together by keeping averaging time interval of $30 \mathrm{~min}$. Correction coefficient for ozone concentration above $1 \mathrm{ppbv}$ for both the instruments is found to be 0.86 . The UV ozone analyzer have minimum detectable limit of about $1 \mathrm{ppbv}$ with response time $50 \mathrm{~s}$. The daily surface meteorological parameters data are used from Indian Meteorological Department (IMD) for the above period at the nearest observatory Nagapattinam $\left(10.8^{\circ} \mathrm{N}, 79.9^{\circ} \mathrm{E}\right.$, $9 \mathrm{~m})$.
Research article

CIndian Society for Education and Environment (iSee)
"Ozone and solar activity" http://www.indjst.org
Sevaraj et al. Indian J.Sci.Technol. 
Fig. 1. Plots of surface $\mathrm{O}_{3}$ and sunspot numbers for May.

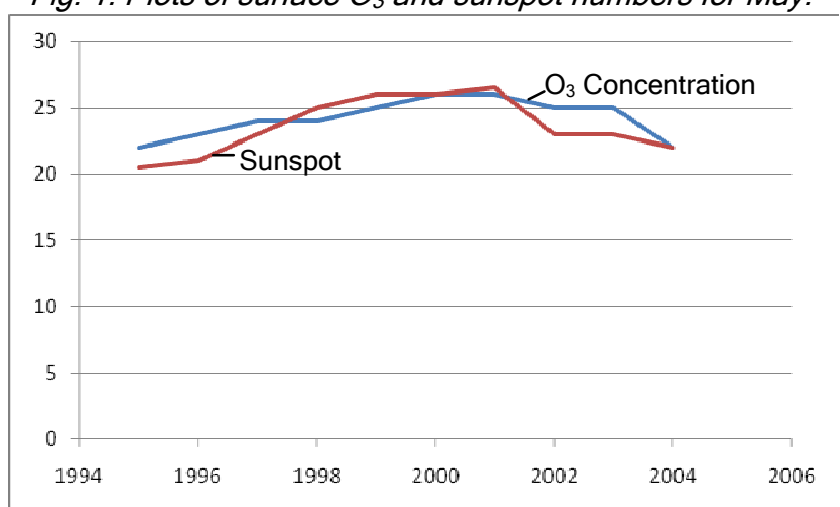

\section{Results and discussion}

It is known that ozone concentrations as well as solar flux in tropical region are more (Hingane, 1988). A number of studies have been reported on troposphere ozone behaviour and concentration from different parts of the world. One recent study about surface ozone concentration at rural, tropical state says that the average ozone concentration are higher $(23 \pm 9 \mathrm{ppbv})$ in May and lower $(17 \pm 7 \quad \mathrm{ppbv})$ in Oct (Debaje et al., 2003). Moreover, surface air temperature is highest (about $36^{\circ} \mathrm{C}$ ) during July whereas higher ozone concentration (23 ppbv) is observed during May instead of July (21 ppbv) due to more cloudiness during the month of July. Further rainfall and sky cover, which are higher during the month of Oct, shows negative correlation with temperature and ozone concentration.

Debaj et al. (2003) in their study indicated that ozone concentrations are higher in May and lie lower in Oct. But, in the same period (1996-2004) ozone concentration are a little bit higher in some particular years with increasing the sunspot numbers. This shows that there is some relation between surface ozone and sunspot numbers.

During periods of maximum sunspots, the sun emits more energy (about $0.1 \%$ more) than during the periods of sunspot minima (Donald Ahrens, 2000). Evidently, the greater number of bright areas (faculae) around the sunspots radiates more energy, which offsets the effects of the dark spot. However, most of this variation is in ultraviolet wavelength, which is absorbed by stratospheric ozone. But ozone concentration varies with the sunspot cycle, reaching a maximum during sunspot maximum. The spectral composition of this variation in irradiance is such that much larger percentage changes take place at ultraviolet wavelengths, with $19 \%$ of the increase taking place between the 200 and $300 \mathrm{~nm}$ region, although only $1.2 \%$ of the total irradiance is emitted in this wavelength region (Lean, 1989).

The solar activity affects the earth's atmosphere, below the ionosphere. Because sunlight is required to produce ozone, concentrations of troposphere ozone are normally higher during the afternoons, during the summer months, and during the maximum solar activity.

Vol. 3 No. 3 (Mar 2010)

ISSN: 0974- 6846

Fig. 2. Plots of surface $\mathrm{O}_{3}$ and sunspot numbers for October

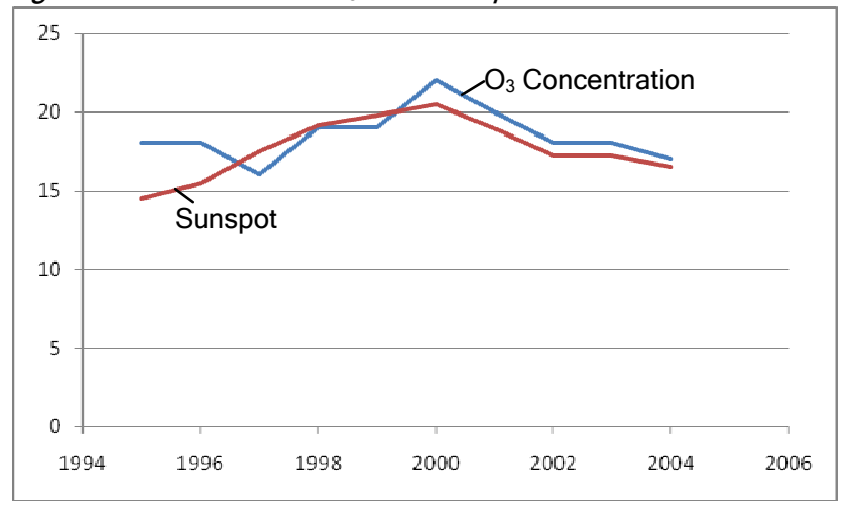

\section{Conclusion}

Ozone concentration increases with rising sunspot number. Generally, solar radiation plays a vital role in the surface ozone concentration. Fig. 1. gives the association between the solar radiation and ozone concentration. Ozone concentration in the month of May, which is the hottest month of the study site is increased with higher amount of solar radiation. Apart from this usual annual trend between ozone concentration and solar radiation, there are some peaks around the year 2001 and 2002. These years are having higher sunspot numbers.

The surface ozone concentration has also a clear diurnal cycle, with the higher values in day time and lower values at night. To determine the seasonal variation of surface ozone concentration, measurements were made for all the months of the year. In summer the surface ozone concentration was the highest compared to the other months. The surface ozone concentration was considerably higher next to May in the month of Oct. The surface ozone concentration is more or less same for all the other months. Variation in the seasonal surface ozone concentration is presented in the Fig. 1 and 2.

The surface ozone concentration depends on metrological conditions such as temperature, solar radiation, wind speed and direction. In this study this relation is not considered. Results of this research revealed that the surface ozone concentration is markedly correlated with sunspot numbers. The surface ozone concentration is higher in the month of May due to the greatest amount of solar radiation. The enhancement of surface ozone concentration has been observed in association with the increasing sunspot numbers. This feature is more significant in May than in Oct.

\section{Acknowledgement}

The authors are thankful to Dr. Debaje IITM Pune, for his constant help and encouragement in preparing the manuscript and the authors wish to thank Udaipur solar observatory for providing sunspots data. 
Table 1. Ozone concentration and sunspot numbers for the period 1996-2004

\begin{tabular}{|c|c|c|c|c|c|c|c|c|c|c|c|c|c|c|c|c|c|c|}
\hline Month & \multicolumn{2}{|c|}{1996} & \multicolumn{2}{|c|}{1997} & \multicolumn{2}{|c|}{1998} & \multicolumn{2}{|c|}{1999} & \multicolumn{2}{|c|}{2000} & \multicolumn{2}{|c|}{2001} & \multicolumn{2}{|c|}{2002} & \multicolumn{2}{|c|}{2003} & \multicolumn{2}{|c|}{2004} \\
\hline & $\mathrm{O}_{3}$ & SSN & $\mathrm{O}_{3}$ & SSN & $\mathrm{O}_{3}$ & SSN & $\mathrm{O}_{3}$ & SSN & $\mathrm{O}_{3}$ & SSN & $\mathrm{O}_{3}$ & SSN & $\mathrm{O}_{3}$ & SSN & $\mathrm{O}_{3}$ & SSN & $\mathrm{O}_{3}$ & SSN \\
\hline JAN & 20 & 10.4 & 20 & 10.5 & 21 & 43.8 & 22 & 82.6 & 22 & 112.9 & 22 & 108.7 & 23 & 114.1 & 22 & 79.5 & 21 & 37.3 \\
\hline FEB & 21 & 10.1 & 21 & 11 & 22 & 49 & 22 & 84.6 & 23 & 116.8 & 22 & 104 & 23 & 107.3 & 23 & 46.2 & 22 & 45.6 \\
\hline MAR & 21 & 9.7 & 21 & 13.5 & 23 & 53.5 & 23 & 83.8 & 23 & 119.9 & 22 & 104.8 & 24 & 98.3 & 24 & 61.5 & 23 & 49.1 \\
\hline APR & 22 & 8.4 & 22 & 16.5 & 23 & 56.6 & 23 & 85.5 & 24 & 120.8 & 23 & 107.5 & 25 & 120.7 & 25 & 60 & 23 & 39.3 \\
\hline MAY & 22 & 8.0 & 23 & 18.5 & 24 & 59.4 & 24 & 90.5 & 25 & 119 & 26 & 108.6 & 26 & 120.8 & 25 & 55.2 & 22 & 41.5 \\
\hline JUN & 21 & 8.5 & 21 & 20.4 & 23 & 62.5 & 22 & 93.1 & 23 & 118.7 & 24 & 109.8 & 23 & 84.3 & 23 & 77.4 & 23 & 43.2 \\
\hline JUL & 19 & 8.4 & 19 & 22.7 & 23 & 65.5 & 21 & 94.3 & 23 & 119.8 & 24 & 111.7 & 22 & 99.6 & 20 & 85 & 22 & 51 \\
\hline AUG & 18 & 8.3 & 19 & 25.1 & 20 & 67.8 & 20 & 97.5 & 20 & 118.6 & 23 & 113.6 & 21 & 116.4 & 19 & 72.7 & 21 & 40.9 \\
\hline SEP & 19 & 8.4 & 19 & 28.4 & 19 & 69.5 & 20 & 102.3 & 21 & 116.3 & 20 & 114.1 & 21 & 109.5 & 19 & 48.8 & 19.6 & 27.7 \\
\hline OCT & 18 & 8.8 & 18 & 31.9 & 16 & 70.5 & 19 & 107.8 & 19 & 114.5 & 22 & 125.7 & 20 & 97.5 & 18 & 65.6 & 17 & 48.4 \\
\hline NOV & 18 & 9.8 & 17 & 35 & 17 & 73 & 19 & 111.0 & 18 & 112.7 & 20 & 106.5 & 19 & 95 & 18 & 67.2 & 18 & 43.7 \\
\hline DEC & 19 & 10.4 & 19 & 39 & 20 & 77.9 & 21 & 111.12 & 21 & 112 & 19 & 132.2 & 18 & 81.6 & 20 & 46.5 & 21 & 17.9 \\
\hline
\end{tabular}

\section{Reference}

1. Butukhanov V P and Lomukhin Yu L (2008) Variations in the surface ozone concentration in the atmosphere over Ulan-Ude, Atmos. Oceanic Phy. 44(4), 467-473.

2. Debaje SB et al., (2003) All surface ozone measurements at tropical rural coastal station, Tranquebar, India, Atmospheric environment, 37, 4911-4916.

3. Donald Ahrens C (2000) Meteorology today, an introduction to weather, climate and the environment, $6^{\text {th }}$ ed., Brooks/Cole - London.

4. Hingane LS (1988) Heating rate due to UV absorption by ozone over India, Mausam , 17, 521551.

5. Lean J (1989) Contribution of ultraviolet irradiance variations to changes in the Sun's total irradiance, Science. 24, 197- 200

6. Mickley LJ, Murti P P, Jacob D J, Logan J A (1999) Radiative forcing from tropospheric ozone calculated with a unified chemistry-climate model, J.Geophys. Res.104, 30153 - 30172

7. Perry and Young, (1977) Handbook of Pollution Analysis Chapman \& Hall Ltd., New York.

8. Singh N and Sontakke NA (1999) On the variability and prediction of rainfall in the post-monsoon season over India, Intl. J. Climatology. 19, 309-339

9. Staudt AC (2003) Sources and chemistry of nitrogen oxides over the tropical pacific, J.Geophys. Res. 108 (D2), 8239. 